\title{
Pengaruh Kualitas Pelayanan dan Kualitas Produk terhadap Kepuasan Konsumen melalui Marketing Relationship
}

\author{
Ike Kusdyah Rachmawati \\ Program Studi Manajemen, ITB Asia Malang, Malang, Indonesia \\ ikekusdyah@gmail.com
}

\begin{abstract}
Competition in providing the best service needs to be done to pamper and give satisfaction to customers, this can be realized by providing something more for customers to enjoy the food and drinks offered even during the current pandemic. This research is quantitative descriptive. This study took service quality and product quality as the independent variables, consumer satisfaction as the dependent variable, and relationship marketing as the intervening variable. The research location is BataPuti Coffee House. The population in this study were people who had visited BataPuti Coffee House. The sample used is as many as 90 respondents to people who have visited the BataPuti Coffee House. The analysis used is Path Analysis Analysis. The results of this study is a significant impact on relationship marketing toward service quality and product quality. service quality and product quality have a significant effect on consumer satisfaction. service quality on customer satisfaction through relationship marketing has a significant effect. Product quality on consumer satisfaction through relationship marketing has a significant effect.
\end{abstract}

Keywords: Consumer Satisfaction, Marketing Relationship, Pandemic, Product Quality, Service Quality

\section{PENDAHULUAN}

Makanan dan minuman masih menjadi kebutuhan pokok konsumen dikala pandemi ini. Denan keterbatasan kondisi karena pandemi, perusahaan mulai mengejar dan memperketat persaingan dalam berbagai faktor. Persaingan dalam memberikan pelayanan yang terbaik juga dilakukan untuk memanjakan konsumen dapat menikmati makanan dan minuman, mulai dari kualitas rasa hingga kecepatan pengantaran menjadi poin utama persaingan. Persepsi para pelanggan tentang mutu suatu usaha berkait erat dengan kualitas pelayanan. Semakin bagus sebuah pelayanan yang diberikan usaha, maka semakin baik pula persepsi kepuasan para pelanggannya. Begitu pula yang terjadi apa bila keadaan berbalik, dimana pelayanan yang diberikan kurang maka akan muncul persepsi kurang memuaskan dari para pelanggan. Usaha peningkatan kualitas pelayanan harus terus menerus dilakukan dalam rangka pemaksimalan kualitas jasa (Alvianna, 2021). Bataputi Coffee House adalah satu dari sekian kafe dengan landscape taman yang senantiasa menawarkan pemandangan alam dan udara yang meenyejukkan. BataPuti Coffee House ini berlokasi di daerah Pandanwangi, Kecamatan Blimbing, Kota Malang. Cafe kopi dengan pemandangan alam ini siap melayani pengunjung mulai pukul 15.00-23.00 WIB setiap hari. Khusus akhir pekan, cafe ini buka hingga pukul 00.00 WIB. Tempatnya yang nyaman dengan pemandangan alam menjadi point "plus" 
tempat ini. Tempat ini juga menawarkan sisi romantis bagi para pasangan dengan fasilitas outdoor lengkap dengan lanskap temaram malamnya. Lebih lagi, kehadiran jembatan gantung juga menarik perhatian para pengunjung untuk melakukan swafoto. Sajian menu Bataputi Coffee House memang lebih mendominasikan kopi, namun sajian yang lain juga ditawarkan untuk memanjakan para pengunjung dan memaksa mereka untuk berlama-lama disini. Dengan kisaran harganya antara 30 ribu rupiah hingga 70 ribu rupiah untuk kopinya, makanan ringannya dihargai antara 30 ribu rupiah hingga 50 ribu rupiah. Harga yang cukup affordable untuk muda-mudi Kota Malang dan sekitarnya.

Selain kualitas pelayanan, cita rasa dan kualitas produk juga menjadi prioritas utama untuk menjaga kepuasan para konsumen. Dalam usaha mempertahankan sebuah bisnis, kualitas produk juga harus tetap dijaga agar tetap bisa mendapatkan tempat dan kepuasan bagi konsumen. Kualitas sebuah produk bertalian erat dengan kapabilitas suatu produk untuk memerankan fungsinya. Hal ini meliputi keseluruhan produk, ketepatan, kemudahan pengoperasian hingga perbaikan. Pasar dipertahankan dengan cara memeberikan kepuasan bagi konsumen, termasuk didalamnya produk yang bermutu dan pelayanan yang baik serta berkualitas (Kotler, 1991). Dapat disimpulkan bahwa, seberapa berkualitasnya sebuah produk bergantung pada seberapa maksimalmnya mereka untuk menjalankan fungsinya sebagai sebuah produk, dengan kata lain semakin dia berfungsi atau merepresentasikan fungsinya maka semakin berkualitas produk tersebut.

Pendekatan relasi atau strategi pemasaran melalui relationship marketing mendapatkan porsi yang cukup signifikan untuk meningkatkan penjualan. Pemasaran hubungan (relationship marketing) didefinisikan sebagai "pemasaran yang memiliki tujuan untuk membangun hubungan yang baik dengan para pelanggan". Marketing relationship diartikan sebagai suatu hubungan yang melekat antara pemasar dengan pelanggan dalam rangka menciptakan kunci pemasaran jangka panjang (Keller, 2012). Membangun hubungan relasi, merupakan sebuah strategi alternatif pemasaran yang saling menguntungkan untuk memelihara, menjaga, dan mewujudkan hubungan baik antara perusahaan dengan pelanggan dlaam jangka yang panjang.

Suatu pengukuran dibutuhkan oleh perusahan kepada konsumen untuk menguji kualitas hubungan keduanya. Apabila kebutuhan dan harapan konsumen terpenuhi melalui pelayanan sebuah perusahaan, maka dapat dikatakan bahwa pelayanan tersebut sudah memuaskan, dan begitupun sebaliknya semakin tidak memuaskannya sebuah pelayanan adalah ketika sebuah perusahaan gagal memenuhi kebutuhan dan harapan para konsumen. Sebagai salah satu pelaku bisnis yang menerima pelanggan atau konsumen, Manajemen BataPuti Coffee House berupaya memberikan pelayanan konsumen yang terbaik meski persaingan café disekitar berlomba-lomba memberikan layanan yang sama. Menghadapi masa new normal, karyawan BataPuti Coffee House terpacu dan bergerak untuk membuat kemudahan pada konsumennya agar tetap bersedia dan setia menjadi pelanggan café, yaitu dengan cara memberikan informasi langsung melalui telepon seluler atau whatsapp. Tim BataPuti Coffee House mampu menginformasikan menu baru, cara pemesanan baru, termasuk pengiriman produk untuk tetap bisa melayani konsumen.

\section{METODE}

Penelitian deskriptif kuantitatif dipilih sebagai metode dalam penelitian ini dengan menatap gambaran terkait situasi atau kejadian. Variabel yang digunakan dalam penelitian ini terdiri atas variabel bebas (kualitas pelayanan dan kualitas produk), Variabel terikat (kepuasan konsumen), dan variabel intervening (relationship marketing). Teknik survey, penyebaran kuesioner, dan telaah pustaka dipilih untuk mengumpulkan data penelitian. Penelitian dilakukan di BataPuti Coffee House berlokasi di daerah Pandanwangi, Kecamatan Blimbing, Kota Malang. Populasi penelitian ini adalah 
Populasi yang menjadi penelitian ini dilihat dari rata-rata konsumen berkisar jika 30 orang per hari dikalikan 30 hari dan dengan perhitungan sampel dengan toleransi error $10 \%$. Berdasarkan perhitungan sampel diatas, 90 responden pada orang yang pernah berkunjung ke BataPuti Coffee House digunakan sebagai sampel. Teknik aksidental digunakan sebagai teknik pengambilan data, dimana sampel diambil secara kebetulan namun objek yang terpilih dan diambil diyakini sebagai sumber data. Analisa Path Model (Analisa Jalur) digunakan seperti yang dapat dilihat pada konsep di Gambar 1 :

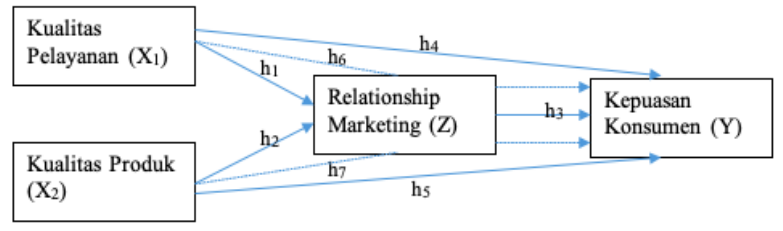

Gambar 1. Kerangka Konseptual

\section{HASIL DAN PEMBAHASAN}

Uji Asumsi Analisis Jalur

Dibawah ini disajikan hasil pemeriksaan dan pengujian lima asumsi yang harus terpenuhi pada analisis jalur.

Hubungan antar variabel bersifat linier dan aditif. Metode Curve fit digunakan untuk menguji linieritas asumsi dengan memanfaatkan software SPSS dengan asumsi linieritas berhipotesis sebagai berikut:

$\mathrm{H}_{0}: \beta_{i}=0$ (tidak terdapat hubungan linier) vs

$\mathrm{H}_{1}: \beta_{i} \neq 0$ (terdapat hubungan linier) dengan

$$
i=1,2,3,4,5
$$

Tabel 1. Model Hubungan Linier Antar Variabel Independen dan Dependen Menggunakan Metode Curve Fit

\begin{tabular}{lccc}
\hline \multicolumn{1}{c}{ Model Hubungan } & $\mathrm{F}$ & $P-$ & \\
Linear Antar Variabel & hitung & value & Hubungan \\
\hline $\begin{array}{l}\text { Kualitas Pelayanan } \\
\text { dengan Relationship }\end{array}$ & & & \\
$\begin{array}{l}\text { Marketing } \\
\begin{array}{l}\text { Kualitas Produk } \\
\text { dengan Relationship }\end{array}\end{array}$ & 24,687 & 0,000 & Linear \\
Marketing & 36,098 & 0,000 & Linear
\end{tabular}

\begin{tabular}{lccc}
\hline \multicolumn{1}{c}{$\begin{array}{c}\text { Model Hubungan } \\
\text { Linear Antar Variabel }\end{array}$} & $\begin{array}{c}\mathrm{F} \\
\text { hitung }\end{array}$ & $\begin{array}{c}P \text { - } \\
\text { value }\end{array}$ & Hubungan \\
\hline $\begin{array}{l}\text { Kualitas Pelayanan } \\
\text { dengan Kepuasan }\end{array}$ & & & \\
$\begin{array}{l}\text { Konsumen } \\
\text { Kualitas Produk } \\
\text { dengan Kepuasan }\end{array}$ & 41,375 & 0,000 & Linear \\
$\begin{array}{l}\text { Konsumen } \\
\text { Relationship Marketing } \\
\text { dengan Kepuasan }\end{array}$ & 53,864 & 0,000 & Linear \\
$\begin{array}{l}\text { Konsumen } \\
\text { Sumber: Data Primer Diolah, 2021 }\end{array}$ & & \\
\hline
\end{tabular}

Berdasarkan Tabel 1, setiap variabel bernilai $\mathrm{P}_{\text {value }}<\alpha=0,05$ sehingga diambil keputusan dengan menolak $\mathrm{H}_{0}$ yang berarti bahwa ketiga variabel independen berhubungan secara linier terhadap variabel dependen.

Selain itu model analisis jalur memerlukan asumsi aditifitas yakni tidak adanya interaksi antar variabel, pada penelitian ini model yang digunakan adalah model sebagai berikut:

$$
\begin{aligned}
& Z_{\text {Relationship }} \text { Marketing }=\rho_{\mathrm{Zx} 1} \mathrm{Z}_{\text {Kualitas }} \text { Pelayanan } \\
& +\rho \mathrm{Zx} 2 Z_{\text {Kualitas }} \text { Produk }+ \\
& \varepsilon_{\text {Relationship Marketing }} \\
& \mathrm{Z}_{\text {Kepuasan }} \text { Konsumen }=\rho_{\mathrm{Yx} 1} \mathrm{Z}_{\text {Kualitas Pelayanan }}+ \\
& \rho_{\mathrm{Yx} 2} Z_{\text {Kualitas }} \text { Produk }+ \\
& \rho_{\text {Yz }} Z_{\text {Relationship }} \text { Marketing }+ \\
& \mathcal{\varepsilon} \text { Kepuasan Konsumen }
\end{aligned}
$$

Model di atas merupakan model yang aditif dikarenakan model tersebut merupakan model pertambahan dan tidak ada interaksi antar variabel. Pembahasan diatas menyimpulkan bahwa asumsi model memiliki hubungan antar variabel yang bersifat linier dan aditif terpenuhi.

Model Rekursif adalah keharusan sebuah model untuk memiliki sistem aliran satu arah ketika melakukan analisis. Selanjutnya, diagram pencar dan bantuan software SPSS dimanfaatkan untuk melakukan pemeriksaan seperti sajian pada Tabel 2 berikut ini. 
Tabel 2. Pola Hubungan pada Plot antar Residual

\begin{tabular}{cc}
\hline Variabel & Pola Hubungan \\
\hline$\varepsilon_{2}$ dengan $\varepsilon_{1}$ & \\
$\varepsilon_{1}$ dengan $\mathrm{ZX}_{1}$ & Menyebar Secara \\
$\varepsilon_{1}$ dengan $\mathrm{ZX}_{2}$ & Acak \\
$\varepsilon_{2}$ dengan $\mathrm{ZX}_{1}$ & \\
$\varepsilon_{2}$ dengan $\mathrm{ZX}_{2}$ & \\
\hline
\end{tabular}

Keterangan:

$\varepsilon_{1}$ : Sisaan variabel Relationship Marketing

$\varepsilon_{2}$ : Sisaan variabel Kepuasan Konsumen

$\mathrm{ZX}_{1}$ : Variabel Kualitas Pelayanan

$\mathrm{ZX}_{2}$ : Variabel Kualitas Produk

Berdasarkan Tabel 2 dapat dilihat bahwa plot antar residual dan plot antar residual dengan setiap variabel independent pada setiap persamaan menyebar secara acak dan tidak membentuk suatu pola. Hal ini menunjukkan bahwa terjadi kebebasan residual sehingga asumsi model rekursif terpenuhi.

1. Variabel endogen minimal dalam skala ukur interval. Data primer dengan skala likert berskala interval digunakan dalam studi ini.

2. Model yang te ranalisis diidentifikasi menurut teori dan konsep yang relevan. Pada penelitian ini, dasar untuk menetukan dimensi yang membentuk suatu variable terlibat didalam model adalah pendapat para ahli, sehingga asumsi mengenai model yang dianalisis diidentifikasi berdasarkan teori dan konsep yang relevan terpenuhi.

\section{Pendugaan Parameter}

Setelah asumsi spenuhnya terpenuhi, pendugaan parameter dilakukan sebagai langkah berikutnya. Koefisien regresi standardize dengan Metode Kuadrat Terkecil (MKT) diduga dalam pendugaan parameter yang digunakan dalam analisis jalur. Metode ini dipilih karena dianggap paling sederhana namun diwkatu yang bersamaan juga memiliki kelemahan yaitu karena keterbatasannya yang hanya dapat digunakan untuk menghitung pengaruh langsung juga tidak langsung. Diagram dan koefisien jalur yang telah terduga dengan bantuan software SPSS tergambar dibawah ini.

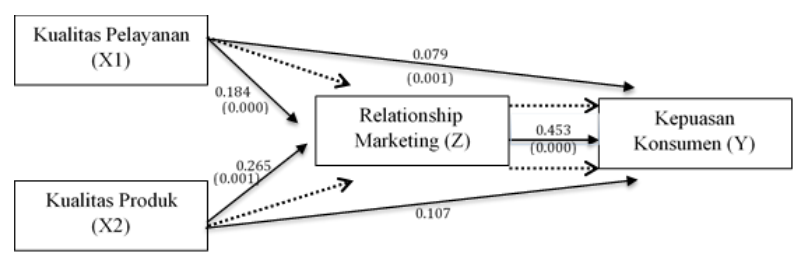

Gambar 2. Diagram dan Koefisien Jalur

Pada Gambar 2 setelah menduga koefisien jalur, maka didapatkan persamaan jalur sebagai berikut:

$$
\begin{array}{llll}
\text { ZRelationship Marketing } & =\rho_{\mathrm{Zx} 1} \mathrm{Z}_{\text {Kualitas }} & \text { Pelayanan } \\
& +\rho_{\mathrm{Zx} 2} \mathrm{Z}_{\text {Kualitas }} & \text { Produk } & + \\
& \varepsilon_{\text {Relationship Marketing }} & \\
\mathrm{Z}_{\text {Kepuasan }} \text { Konsumen } & =\rho_{\mathrm{Yx} 1 \mathrm{Z}_{\text {Kualitas }}} \text { Pelayanan } & + \\
& \rho_{\mathrm{Yx} 2} \mathrm{Z}_{\text {Kualitas }} & \text { Produk } & + \\
& \rho_{\mathrm{Yz}} \mathrm{Z}_{\text {Relationship }} & \text { Marketing } & + \\
& \varepsilon_{\text {Kepuasan Konsumen }}
\end{array}
$$

\section{Pengujian Hipotesis}

Pengujian hipotesis dilakukan dengan tujuan untuk mengetahui signifikansi model yang terbentuk. Pengujian secara parsial dalam penelitian ini menggunakan hipotesis sebagai berikut:

$$
\begin{aligned}
& \mathrm{H}_{0}: \rho_{\mathrm{zx} 1}=0 \text { vs } \mathrm{H}_{1}: \rho_{\mathrm{zx} 1} \neq 0 \\
& \mathrm{H}_{0}: \rho_{\mathrm{zx} 2}=0 \mathrm{vs} \mathrm{H}_{2}: \rho_{\mathrm{zx} 1} \neq 0 \\
& \mathrm{H}_{0}: \rho_{\mathrm{yx} 1}=0 \mathrm{vs} \mathrm{H}_{3}: \rho_{\mathrm{yx} 1} \neq 0 \\
& \mathrm{H}_{0}: \rho_{\mathrm{yx} 2}=0 \mathrm{vs} \mathrm{H}_{3}: \rho_{\mathrm{yx} 2} \neq 0 \\
& \mathrm{H}_{0}: \rho_{\mathrm{yz}}=0 \mathrm{vs} \mathrm{H}_{3}: \rho_{\mathrm{yz}} \neq 0
\end{aligned}
$$

Pada gambar dibawah ini nilai yang diberi tanda kurung pada Gambar 3 merupakan nilai peluang untuk setiap koefisien jalur.

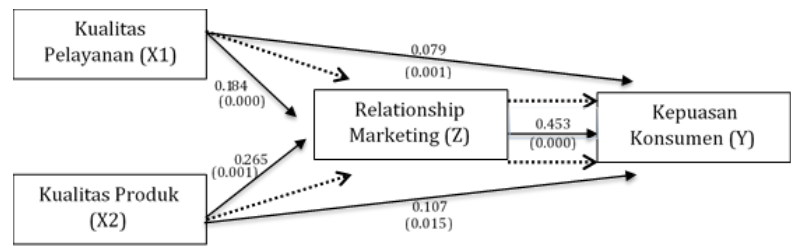

Gambar 3. Diagram dan Hasil Pengujian Hipotesis 


\section{Validitas Model}

Validitas model yang diperoleh dalam analisis jalur juga diperlukan selain memenuhi beberapa asumsi.

\section{Koefisien Determinasi Total}

Koefisien determinasi total dibutuhkan untuk dikalkulasi dengan tujuan untuk mengetahui varietas data yang dapat dijelaskan. Koefisien determinasi dan pengaruh sisaan pada setiap persamaan juga dilibatkan dalam pehitungan koefisien determinasi total sebagaimana disajkan secara singkat pada Tabel 3 .

Tabel 3. Koefisien Determinasi, Pengaruh Sisaan pada Setiap Persamaan, dan Koefisien Determinasi Total

\begin{tabular}{lccc}
\hline \multicolumn{1}{c}{ Variabel } & $\begin{array}{c}\text { Koefisien } \\
\text { Determin } \\
\text { asi }\left(\mathrm{R}^{2}\right)\end{array}$ & $\begin{array}{c}\text { Pengaru } \\
\mathrm{h} \text { Sisaan } \\
\left(\rho_{\mathrm{e}}\right)\end{array}$ & $\begin{array}{c}\text { Koefisien } \\
\text { Determinas } \\
\mathrm{i} \text { Total }\left(\mathrm{R}_{\mathrm{t}}^{2}\right)\end{array}$ \\
\hline $\begin{array}{l}\text { Relationship } \\
\text { Marketing (Z) }\end{array}$ & 0,379 & 0,819 & 0,453 \\
$\begin{array}{l}\text { Kepuasan } \\
\text { Konsumen }(\mathrm{Y})\end{array}$ & 0,617 & 0,954 & \\
\hline
\end{tabular}

Koefisien determinasi total dalam studi ini adalah sebesar 0,453 sehingga kesimpulan yang dapat diambil adalah model dapat menjelaskan varietas data sebesar 45,3\%, sementara itu sisanya dijelaskadiuraikan oleh variabel lain yang belum terdapat dalam model. Dengan kata lain, Kepuasan konsumen yang dipengaruhi secara langsung dan tidak langsung oleh relationship marketing, Kualitas pelayanan, dan kualitas produk adalah sebesar 45,3\% dan sisanya sebesar 54,7\% dipengaruhi oleh variabel lain yang belum termasuk ke dalam model.

\section{Pengaruh pada Analisis Jalur}

Korelasi pengaruh langsung, pengaruh tidak langsung, dan pengaruh total terhadap relationship marketing dan kepuasan konsumen tersaji dalam Tabel 4.
Tabel 4. Pengaruh pada Analisis Jalur

\begin{tabular}{|c|c|c|c|}
\hline Variabel & $\begin{array}{l}\text { Pengaruh } \\
\text { Langsung }\end{array}$ & $\begin{array}{l}\text { Pengaruh } \\
\text { Tidak } \\
\text { Langsung }\end{array}$ & $\begin{array}{r}\text { Pengaruh } \\
\text { Total }\end{array}$ \\
\hline \multicolumn{4}{|l|}{ Kualitas } \\
\hline \multicolumn{4}{|l|}{$\begin{array}{l}\text { Pelayanan } \\
\text { terhadap }\end{array}$} \\
\hline \multicolumn{4}{|l|}{ Relationship } \\
\hline Marketing & 0,184 & - & 0,184 \\
\hline \multicolumn{4}{|l|}{$\begin{array}{l}\text { Kualitas Produk } \\
\text { terhadap }\end{array}$} \\
\hline \multicolumn{4}{|l|}{ Relationship } \\
\hline Marketing & 0,265 & - & 0,265 \\
\hline Kualitas & & $0,184 \times 0,453=$ & \\
\hline Pelayanan & & 0,083 & \\
\hline terhadap & & (Melalui & \\
\hline Kepuasan & & Relationship & \\
\hline Konsumen & 0,079 & Marketing) & 0,162 \\
\hline Kualitas Produk & & $0,265 \times 0,453=$ & \\
\hline terhadap & & 0,120 & \\
\hline Kepuasan & & (Melalui & \\
\hline \multirow{2}{*}{ Konsumen } & & Relationship & \\
\hline & 0,107 & Marketing) & 0,227 \\
\hline \multicolumn{4}{|l|}{ Relationship } \\
\hline \multicolumn{4}{|l|}{$\begin{array}{l}\text { Marketing } \\
\text { terhadap }\end{array}$} \\
\hline \multicolumn{4}{|l|}{ Kepuasan } \\
\hline Konsumen & 0,453 & - & 0,453 \\
\hline
\end{tabular}

Berdasarkan Tabel 4 dapat diketahui jika relationship marketing berpengaruh paling besar secara total terhadap kepuasan konsumen secara langsung sebesar 0,453. kualitas pelayanan mempengaruhi kepuasan konsumen secara tidak langsung melalui relationship marketing sebesar 0,083, dan pengaruh total kualitas pelayanan terhadap kepuasan konsumen sebesar 0,162. kualitas produk mempengaruhi kepuasan konsumen secara tidak langsung melalui relationship marketing sebesar 0,120 , dan pengaruh total kualitas produk terhadap kepuasan Konsumen sebesar 0,227. Kualitas pelayanan memiliki hubungan langsung terhadap relationship marketing sebesar 0,184. Kualitas produk memiliki hubungan langsung terhadap relationship marketing sebesar 0,265. Penelitian ini mendukung penelitian yang dilakukan oleh (Rachmawati et al., 2020)(Hariyanti et al., 2020) dimana untuk membuat kepuasan konsumen dibutuhkan pembuktian adanya kualitas produk yang baik dan pelayanan yang prima. Selain itu hubungan dengan pelanggan dalam meningkatkan kepuasan konsumen perlu juga dilakukan inovasi dan ciri pembeda dengan entrepreneurial marketing (Hidayatullah, 
Windhyastiti, et al., 2020) (Hidayatullah, Rachmawati, et al., 2020). Selanjutnya harga juga perlu dipertimbangkan dalam menjaga kepuasan dari konsumen seperti penelitian yang dilakukan oleh (Hidayatullah, Rachmawati, et al., 2020)(Kusdyah, 2012) (Alvianna, 2021). Kualitas informasi tentang produk yang ditawarkan dan penggunaan media sosial juga sangat berpengaruh dalam penentuan kepuasan konsumen (Pratama, 2021)(Rachmawati, 2020)(Amelia \& Hidayatullah, 2020).

\section{Kesimpulan}

Bersumber pada hasil penelitian dan analisa data yang telah dilakukan terkait pengaruh kualitas pelayanan dan kualitas produk terhadap kepuasan konsumen melalui relationship marketing pada Bataputi Coffee House, dapat disimpulkan: 1) kualitas pelayanan berpengaruh signifikan terhadap relationship marketing 2) Kualitas produk berpengaruh siginifikan terhadap relationship marketing, 3) Relationship marketing berpengaruh signifikan terhadap kepuasan konsumen, 4) Kualitas pelayanan berpengaruh signifikan terhadap kepuasan konsumen, 5) Kualitas produk mempunyai pengaruh signifikan terhadap kepuasan konsumen, 6). Kualitas pelayanan terhadap kepuasan konsumen melalui relationship marketing mempunyai pengaruh signifikan, 7) Kualitas produk terhadap kepuasan konsumen melalui relationship marketing berpengaruh signifikan.

Berdasar hasil penelitan tersebut BataPuti Coffee House harus memperhatikan kualitas layanan terutama dalam kecepatan pelayanan dan kualitas produk terutama dalam kualitas makanan yang selain harus mempunyai "taste" enak juga sesuai dengan harga yang ditawarkan. Selain itu, BataPuti Coffee House harus dapat menjalin hubungan jangka panjang dengan pelanggan misalnya dengan menawarkan member card dengan diskon khusus pelanggan.

\section{DAFTAR PUSTAKA}

Alvianna, S. (2021). Pengaruh Kualitas Harga Layanan dan Kepuasan terhadap Kesetiaan Usia Millenial Berkunjung ke Tempat Wisata. Media Wisata, 18(1), 69-80.

https://doi.org/10.36276/mws.v18i1.78

Amelia, R., \& Hidayatullah, S. (2020). The Effect of Instagram Engagement to Purchase Intention and Consumers , Luxury Value Perception as the mediator in the Skylounge Restaurant. International Journal of Innovative Science and Research Technology, 5(4), 958-966.

Hariyanti, A. O., Hidayatullah, S., \& Prasetya, D. A. (2020). Analysis of the Acceptance and Use of Mobile Banking Services Using the Unified Theory of Acceptance and Use of Technology ( Case Study of. 5(1), 254-262.

Hidayatullah, S., Rachmawati, I. K., Aristanto, E., Waris, A., \& Patalo, R. G. (2020). Peran Sistem Informasi Pemasaran, Kualitas Pelayanan dan Entrepreneurial marketing serta Kepuasan Terhadap Loyalitas Generasi Milenial Berkunjung ke Tempat Wisata. Jurnal Ilmiah Bisnis Dan Ekonomi Asia. https://doi.org/10.32812/jibeka.v14i1.18 4

Hidayatullah, S., Windhyastiti, I., Patalo, R. G., \& Rachmawati, I. K. (2020). Citra Destinasi: Pengaruhnya terhadap Kepuasan dan Loyalitas Wisatawan yang Berkunjung ke Gunung Bromo. 8(1), 96-108.

Keller, K. \&. (2012). Manajemen Pemasaran. 1.

Kotler, P. (1991). Marketing management: analysis, planning, implementation and control. In Journal of Marketing Management.

Kusdyah, I. (2012). Persepsi Harga, Persepsi Merek, Persepsi Nilai, dan Keinginan Pembelian Ulang jasa Klinik Kesehatan. Jurnal Manajemen Pemasaran. https://doi.org/10.9744/pemasaran.7.4.2 5-32 
Pratama, B. (2021). Mediation Effect of Customer Satisfaction from the Relationship between System Quality, Information Quality, and Service Quality towards Interests of Tourist Visiting in East Java Park 3. 6(1), 95100.

Rachmawati, I. K. (2020). Collaboration Technology Acceptance Model, Subjective Norms and Personal Innovations on Buying Interest Online. International Journal of Innovative Science and Research Technology, 5(11).
Rachmawati, I. K., Bukhori, M., Majidah, Y., Hidayatullah, S., \& Waris, A. (2020). Analysis of use of mobile banking with acceptance and use of technology ( Utaut ). International Journal of Scientific \& Technology Research. 9(08),534-540 